\title{
Effects of maternal psychosocial and family sosioeconomics on cancer treatment compliance in children
}

\author{
Linda Wati ${ }^{\mathrm{a}}$, Selvi Nafianti ${ }^{\mathrm{b}}$, Elmeida Effendy ${ }^{\mathrm{c}^{*}}$ \\ ${ }^{a}$ dr.lindawati85@gmail.com \\ ${ }^{a}$ Resident of Department of Child Health, Medical School, Universitas Sumatera Utara/Adam Malik Hospital, Medan \\ ${ }^{b}$ Hematology Oncology Consultant of Department of Child Health, Medical School, Universitas Sumatera Utara/Adam Malik Hospital, \\ Medan \\ ${ }^{c}$ Biologic Consultant of Department of Psychiatri, Medical School, Universitas Sumatera Utara, Medan
}

\begin{abstract}
Background: Childhood cancer is a chronic life-threatening disease and requires a variety of therapies. The key to successful treatment is early detection and treatment adherence. Parental psychosocial and socioeconomics are factors that support a successful treatment.

Objective: To determine the differences in the influence of maternal psychosocial and socioeconomics on adherence to cancer treatment in children.

Method: A cohort study in pediatric patients with cancer and their mothers who were treated at Haji Adam Malik General Hospital, Medan in June 2019-April 2020. Maternal psychosocial assessment with the IES-R questionnaire after knew the diagnosis of cancer in her child and socioeconomic assessment through a questionnaire. Cancer treatment adherence was assessed for six months undergoing treatment. Bivariate analysis used the fisher's exact test to assess differences in the effect of each variable.

Result: Of the 47 subjects observed, it was found $14.9 \%$ of children with cancer were not adherent the treatment. For the research data analyzed there was no significant difference between maternal psychosocial status, education and occupation of the mother, and residence ownership towards the adherence to cancer treatment in children. Total family income had a significant effect on adherence to cancer treatment in children $(p=0.042)$, even though all patients used the National Health Insurance (JKN).

Conclusion: Total amount of family income used as an indicator of socioeconomic status has an influence on adherence of cancer treatment in children.
\end{abstract}

Published by IJRP.ORG. Selection and/or peer-review under responsibility of International Journal of Research Publications (IJRP.ORG)

Keyword: Maternal psychosocial; socioeconomic; cancer treatment adherence; cancer in children

\section{Introduction}

Cancer in children is a chronic disease that requires invasive and life-threatening therapy (Wong and Chan, 2006; Chao, 2002). As many as 11,000 children are diagnosed with cancer each year in Indonesia (Pusat Data dan Informasi Kementerian Kesehatan Republik Indonesia, 2015) and Haji Adam Malik General Hospital, Medan had 109 cases of cancer in children under 15 years of age during 2017. Recently, the life expectancy of children with childhood cancer has increased to 10 years, but the length of life expectancy varies from person to person. Several factors can influence it, such as medication adherence, access to treatment, socioeconomic, culture, race, environment, social support, and biology (Harper et al., 2012; Jabeen et al., 2016; Abrahao et al., 2015). 
Low adherence to treatment can worsen disease conditions, death, and increase the need for health costs (Osterberg and Blaschke, 2005). A study in Yogyakarta found that treatment interruptions were the main cause of treatment failure in children with acute lymphoblastic leukemia. The discontinuation of cancer treatment in children can be caused by various factors that still need further investigation (Mostert et al., 2006).

Parental psychosocial is one of the factors that can influence treatment decisions. The psychosocial status of the parents themselves is formed from the results of the coping response after their child is diagnosed with cancer, where the parents feel it is the heaviest pressure in their life (Wong and Chan, 2006; Perricone et al., 2012; Okado et al., 2016). Another factor that influences the success of treatment is socioeconomic, where costs are still an obstacle, even though the National Health Insurance (JKN) program from the government has been implemented (Jabeen et al., 2016; Mostert et al., 2006; Presiden Republik Indonesia, 2013). Therefore, in an effort to improve medication adherence, psychosocial and socioeconomic assessments need to be considered in order to assess mental strength and beliefs in facing treatment (Purnamasari and Rini, 2018). There was the reason that led researchers to investigate whether parental psychosocial and family socioeconomic influence on adherence to cancer treatment in children at the Haji Adam Malik General Hospital, Medan.

\section{Methods}

\subsection{Study Design}

A cohort study assessed the psychosocial influence of parents, especially mothers and family socioeconomics, on adherence to cancer treatment in children at Haji Adam Malik General Hospital, Medan, North Sumatra.

\subsection{Population and Sample}

The sample of the study was childhood cancer patients who met the inclusion and exclusion criteria. The inclusion criteria were children aged 1 month - 18 years who were diagnosed with cancer within one week and their mothers were Indonesian citizens. Exclusion criteria were subjects who died or experienced a change in diagnosis during monitoring, cases of relapse, and the subject's mother had a history of mental disorders. Samples were collected from June 2019-November 2019.

\subsection{Assessment Procedure}

\subsubsection{Maternal Psychosocial}

The psychosocial status of mothers with childhood cancer were assessed through the Impact of Events Scale-Revised (IES-R) questionnaire which assesses post traumatic stress with scoring, not at all $=0$, a little bit $=1$, moderately $=2$, quite a bit $=3$, and extremely $=4$. The total IES-R score 1-11: no symptoms of post traumatic stress, 12-32: symptoms of post traumatic stress, and $\geq 33$ : post traumatic stress disorder.

\subsubsection{Socioeconomic}

The indicators were maternal education, maternal occupation, family income, residence ownership, and health insurance. Low education category for those who do not attend school, finish primary or junior high school; medium for finish high school or vocational high school; high for finish college. Working mother is mother who has job other than housewives. Family income is the total income of the father and mother each month. We use the provisions of the regional minimum wage (UMR) in North Sumatra in 2019 as a limit on family income, which is IDR 2,303,403.43. Owned house category if the house occupied is owned by the head of the household or one of the household members. Health insurance that is used during treatment, among others, JKN, private insurance, and no insurance.

\subsubsection{Treatment Adherence}

Treatment adherence was assessed for six months via a chemotherapy protocol. Non-adherence if failed to initiate or continue therapy for $\geq$ four weeks. 


\subsection{Ethical Considerations}

This study received approval from the Research Ethics Committee of the Faculty of Medicine, University of North Sumatra / Haji Adam Malik General Hospital.

\subsection{Statistical Analysis}

Data processing was performed using a computerized system of Statistical Package for Social Sciences for Windows (SPSS) version 21. Bivariate analysis used fisher's exact test with a value of $\mathrm{P} \leq 0.05$ was used to indicate statistically significant difference.

\section{Results}

The total sample was 47 subjects who met the inclusion and exclusion criterias. Characteristic data (Table 1) with men $(59.6 \%)$ and women $(40.4 \%)$, the median age was 6 years, and dominated by liquid cancer $(76.6 \%)$. After 6 months of monitoring, 7 subjects (14.9\%) did not adhere to chemotherapy treatment.

The mean age of the mother's subjects was 37.49 years old, with the majority of mothers had medium education $(42.6 \%)$ and unemployment $(78.7 \%)$. Maternal psychosocial status had post traumatic stress disorder $(80.9 \%)$ and symptoms of post traumatic stress $(19.1 \%)$ after had known the malignancy suffered by their child. Family income per month was $\geq$ UMR (76.6\%) and the residence ownership was owned (61.7\%). All study subjects used JKN insurance during treatment.

Table 1. Characteristics of subjects and mothers of subjects

\begin{tabular}{cc}
\hline \multicolumn{1}{c}{ Characteristics } & $\mathrm{n}=47$ \\
\hline Subjects & \\
Gender (n/\%) & $28(59.6 \%)$ \\
Male & $19(40.4 \%)$ \\
Female & $6(1-16)$ \\
Age, Year (median/range) & $36(76,6 \%)$ \\
Type of Cancer (n/\%) & $11(23,4 \%)$ \\
Liquid cancer & \\
Solid cancer & $40(85.1 \%)$ \\
Treatment Adherence (n/\%) & $7(14,9 \%)$ \\
Obey & \\
Not obey & $37,49(6,433)$ \\
Subjects & $15(31,9 \%)$ \\
Age, Year (mean/SD) & $20(42,6 \%)$ \\
Education (n/\%) & $12(25,5 \%)$ \\
Low & $37(78,7 \%)$ \\
Medium & $10(21,3 \%)$ \\
Occuph & \\
Unemployment (n/\%) & \\
Employment & $38(80,9 \%)$ \\
Maternal psychosocial status (n/\%) & $9(19,1 \%)$ \\
Post traumatic stress disorder & \\
Post traumatic stress symptoms & $11(23,4 \%)$ \\
Family Income (n/\%) & $36(76,6 \%)$ \\
UMR & \\
UMR & $18(38,3 \%)$ \\
Own & $29(61.7 \%)$ \\
\hline
\end{tabular}


After bivariate analysis (table 2), there was no significant difference in the proportion of maternal psychosocial status, maternal education, maternal occupation, and residence ownership with adherence to cancer treatment in children. However, the amount of family income had a significant difference in the proportion of adherence to cancer treatment in children $(\mathrm{p}=0.042)$.

Tabel 2. Differences in maternal psychosocial status, maternal education, maternal occupation, family income, and residence ownership on medication adherence

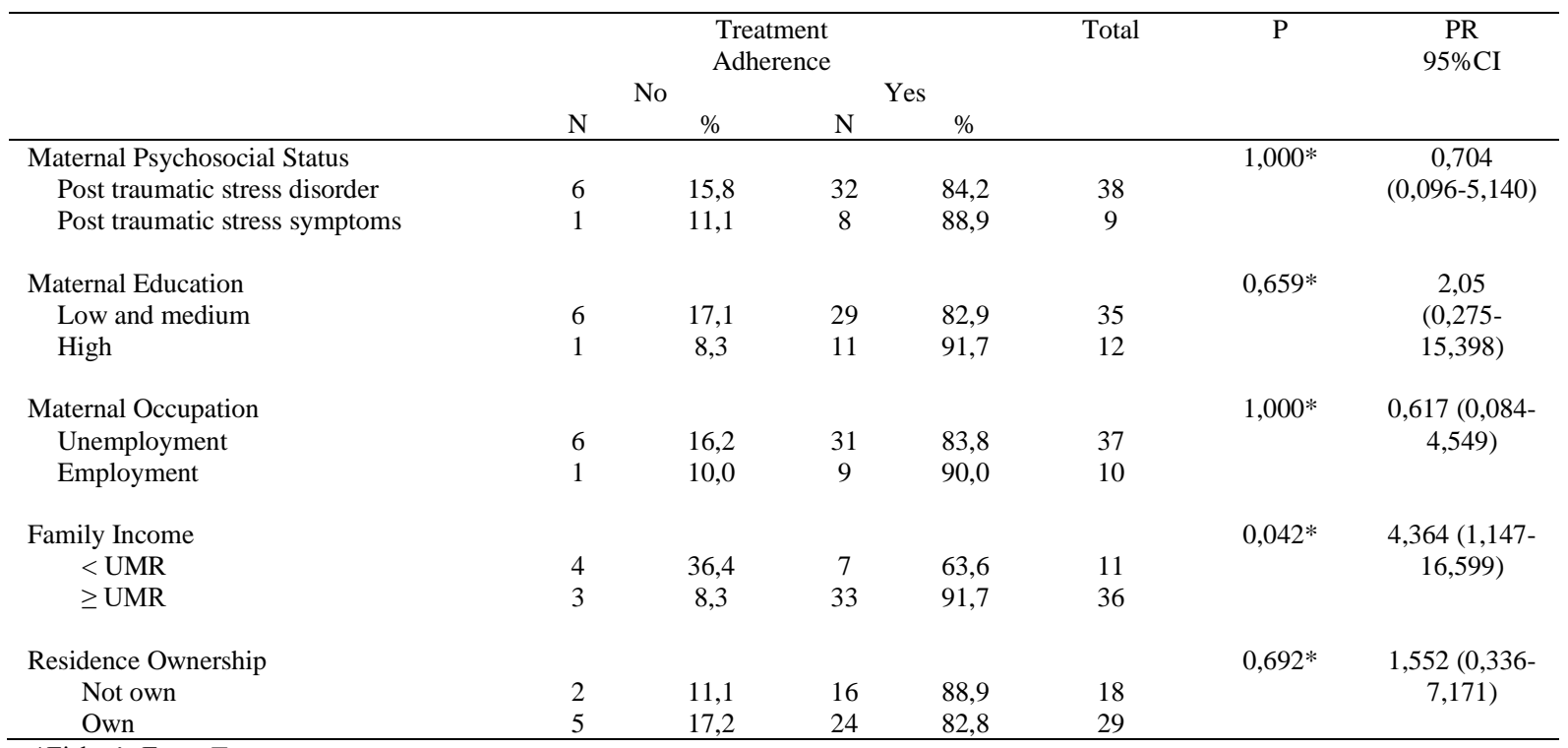

*Fisher's Exact Test

\section{Discussion}

The key to the success of cancer treatment in children is early detection and adherence to treatment, but in fact treatment adherence is often a problem (Mostert et al., 2006, Bleyer et al., 2016). An American study found the influence of children's age, family socioeconomic status, and parenting methods on adherence to cancer treatment in children (Manne et al., 1993). This study found 7 out of 47 subjects (14.9\%) did not comply their chemotherapy treatment because they wanted to try alternative treatments, were afraid of the effects of chemotherapy, and the influence of family or environmental decisions. The results of this study are in line with the research of Davies and Lilleyman, who had 10-40\% incidence of non-adherence to oral chemotherapy treatment of acute lymphoblastic leukemia in children (Davies and Lilleyman, 1995). Likewise with research at Prof. Dr. RD Kandou hospital, Manado for 143 child cancer patients found 68 patients neglected treatment, 40 patients refused therapy, and 28 patients started treatment but then dropped out of treatment (Mostert et al., 2012).

Risk factors that affect treatment adherence of children with cancer include demographic factors (age, ethnicity, race, socioeconomic status), treatment factors (length of treatment, complexity of treatment, side effects, treatment methods, physical characteristics of drugs), individual factors (perception of disease, coping and adaptation, locus of control, anxiety, self-esteem), family factors (family support, parental trust, effects of disease on family life, anxiety), and other factors (human error, forgetfulness, relationship with doctors) (Pritchard et al., 2006). This study tried to examine maternal psychosocial and family socioeconomic factors, in which mothers had chosen as parents' representatives because mothers play a major role in decision making, drug administration, providing comfort and support, planning family activities, handling children's behavior problems, observers, and responsible supervisors (McGrath, 2001; Svavarsdottir, 2005). 
Diagnosis of cancer in children will give a fear and worry to the patient and family, especially parents (Wong and Chan, 2006; Purnamasari and Rini, 2018). That is also a traumatic event and changes family life (Okado et al., 2016; Kohlsdorf and Junior, 2012; Jingting et al., 2017; Kazak et al., 2005). Likewise, the treatment and medication need an understanding of the parent or caregiver, so that to be ready to face these challenges. A maladaptive adjustment process can lead to psychosocial disorders such as distress, depression, anxiety, and post traumatic stress (Kohlsdorf and Junior 2012). This study assessed the mother's psychosocial status through the IES-R questionnaire by assessed the degree of distress after the diagnosis of cancer in her child, with the result that the mother experienced symptoms of post traumatic stress (19.1\%) and post traumatic stress disorder $(80.9 \%)$. These results are in accordance with the study of Kazak et al, which found that $68 \%$ of mothers and $57 \%$ of fathers of children undergoing cancer treatment experienced moderate to severe post traumatic stress symptoms where the diagnosis and treatment of cancer was a traumatic event (Kazak et al., 2005; Kazak et al., 2001).

The effects of parental stress due to their child's cancer include the risk of poor psychological adjustment; negative effects on children's social, emotional and behavioral life on cancer diagnosis and treatment; impaired parents' cognitive abilities to support children's health care; and related to treatment adherence (Streisand et al., 2001). The results of this study did not find a significant difference between maternal psychosocial status and treatment adherence. This is probably because all maternal subjects experienced symptoms and disorders of post traumatic stress so that they cannot be compared with those who did not experienced post traumatic stress. Experts consider the indirect effects of parental stress on adherence through avoidance behavior, which is a symptom of post traumatic stress disorder (Rabineau et al., 2008). On the other hand, Best et al found a relationship between parental stress or anxiety with events such as discussed their child's illness, followed treatment schedules, saw other children who are sick, and looked for information about invasive measures, even though $4 \%$ of mothers and $3 \%$ of fathers avoided the schedule control (Best et al., 2001).

Socioeconomic disparities are the most fundamental cause of health inequalities (Adler and Newman, 2002). The cure rate for childhood cancer was up to $80 \%$ in high-income countries, but less than $35 \%$ in lowincome countries (Smith et al., 2010). Based on research by Arora et al, the cause of 50-60\% of cases of cancer treatment failure in children in low-income countries was treatment non-compliance (Arora et al., 2007). This study found a significant difference in the amount of family income on treatment adherence ( $p=$ 0.042), even though all patients used JKN. During treatment, they are also need transportation, lodging if the child is going to undergo one day care or a waiting list because the room is full, food costs, and phone costs (Punamasari and Rini, 2018; Jingting et al., 2017; Adler and Newman 2002; Dockerty et al., 2003). The same thing was found in research at Dr. Sardjito hospital, Yogyakarta where financial problems as the main cause (93\%) of patients refused or ignored treatment (Mostert et al., 2006). In addition, research at Prof. Dr. RD Kandou hospital, Manado found a significant difference in treatment outcomes between rich and poor patients $(\mathrm{P}<0.0001)$ with an OR of $3.3(95 \% \mathrm{CI}: 1.4-8.1, \mathrm{P}=0.006)$ in ignoring treatment. Research in Manado also found that 22 families (55\%) had experienced a decrease income since starting treatment, 19 fathers $(48 \%)$ and 4 mothers (10\%) lost their jobs (Mostert et al., 2012). The mechanism of the influence of socioeconomic factors on cancer treatment in children is still uncertain (Mogensen et al., 2018). Some hypotheses try to explain the mechanism, such as a good socioeconomic perspective that would enable parents to refer their children to better facilities or see second opinion with other experts (Adam et al., 2016). Another hypothesis relates socioeconomic conditions with the ability and sense of responsibility of parents to treat their children (Mogensen et al., 2018).

The socioeconomic status has traditionally been determined also by education and employment. Education can provide knowledge and life skills for a person to be able to access information and resources in improving health (Adler and Newman, 2002). Work is a series of tasks designed to be done by one person and in return for a wage and salary according to the qualifications and severity of the work (Badan Pusat Statistik, 2002). However, this study did not find a significant difference in the proportion between education and occupation 
of mothers with treatment adherence. Similar to the study by Bonilla et al, where the mother's educational status did not significantly affect treatment adherence when analyzed multivariate with income (Bonilla et al., 2009). In contrast to research at Dr. Sardjito hospital, Yogyakarta found differences in the effect of parental education levels on life expectancy of children with cancer (Mostert et al., 2006).

This study has limitations, where the researcher followed treatment adherence only for 6 months and did not assess other socioeconomic factors, such as the distance between residence and hospital, type of transportation, accommodation, number of siblings, residence status such as electricity, water, number of rooms, as well as culture. Long distances can hinder treatment due to time, cost, difficulty scheduling controls, difficulty getting medicines or groceries (Okumu et al., 2017). The number of siblings can influence the psychosocial of parents and the patient's treatment related to changes in relationships between family members, a sense of lack of parental attention, maladaptive psychology, unmet needs, the burden of helping care for sick and household chores (Jingting et al., 2017; Gerhardt et al., 2015; McGrath et al., 2005). Differences in cultural perceptions about cancer will provide different treatment responses (Kohn et al., 2009). Psychosocial assessment of parents and socioeconomic families of pediatric cancer patients is needed before starting treatment so that the adaptation process of patients and parents can be controlled and are better prepared for treatment. In this case, pediatric oncologists need to collaborate with various multidisciplinary disciplines, such as several other specialist doctors, nurses, pharmacists, psychologists and foundations or social groups in assisting families and patients during treatment (Bleyer et al., 2016).

\section{Conclusion}

Total amount of family income used as an indicator of socioeconomic status has an influence on adherence of cancer treatment in children.

\section{Acknowledgements}

The researcher would like to thank all staff of the Pediatric Hematology Oncology division at the Faculty of Medicine, University of North Sumatra and Sri Sofyani, Wisman Dalimunthe, and Ayodhia Pitaloka Pasaribu for their time and guidance.

\section{References}

Abrahão, R., Lichtensztajn, D. Y., Ribeiro, R. C., Marina, N. M., Keogh, R. H., Marcos-Gragera, R., ... \& Keegan, T. H., 2015. Racial/ethnic and Socioeconomic Disparities in Survival Among Children with Acute Lymphoblastic Leukemia in California, 19882011: A population-based Observational Study, Pediatric Blood \& Cancer 62, p. 1819-1825.

Adam, M., Rueegg, C. S., Schmidlin, K., Spoerri, A., Niggli, F., Grotzer, M., ... \& Kuehni, C. E., 2016. Socioeconomic Disparities in Childhood Cancer Survival in Switzerland, International Journal of Cancer 138, p. 2856-2866.

Adler, N. E., \& Newman, K., 2002. Socioeconomic Disparities in Health: Pathways and Policies, Health Affairs 21, p. 60-76.

Arora, R. S., Eden, T., \& Pizer, B., 2007. The Problem of Treatment Abandonment in Children from Developing Countries with Cancer, Pediatric Blood \& Cancer 49, p. 941-946.

Badan Pusat Statistik., 2002. Penjelasan, in “Klasifikasi Baku Jenis Pekerjaan Indonesia”. Badan Pusat Statistik, Jakarta, p. v-xxi.

Best, M., Streisand, R., Catania, L., \& Kazak, A. E., 2001. Parental Distress During Pediatric Leukemia and Posttraumatic Stress Symptoms (PTSS) After Treatment Ends, Journal of Pediatric Psychology 26, p. 299-307.

Bleyer, A., Ritchey, A. K., Friehling, E., 2016. Principle of Treatment, in "Nelson Textbook of Pediatrics" R. M. Kiegman, B. F. Stanton, J. W. St Geme, N. F. Schor, Editor. Elsevier, Kanada, p. 2426-2436.

Bonilla, M., Rossell, N., Salaverria, C., Gupta, S., Barr, R., Sala, A., ... \& Sung, L., 2009. Prevalence and Predictors of Abandonment of Therapy Among Children with Cancer in El Salvador, International Journal of Cancer 125, p. 2144-2146.

Davies, H. A., \& Lilleyman, J. S., 1995. Compliance with Oral Chemotherapy in Childhood Lymphoblastic Leukaemia, Cancer Treatment Reviews 21, p. 93-103.

Dockerty, J. D., Skegg, D. C. G., \& Williams, S. M., 2003. Economic Effects of Childhood Cancer on Families, Journal of Paediatrics and Child Health 39, p. 254-258.

Gerhardt, C. A., Lehmann, V., Long, K. A., \& Alderfer, M. A., 2015. Supporting Siblings as a Standard of Care in Pediatric Oncology, Pediatric Blood \& Cancer 62, p. S750-S804. 
Harper, F. W., Penner, L. A., Peterson, A., Albrecht, T. L., \& Taub, J., 2012. Children's Positive Dispositional Attributes, Parents' Empathic Responses, and Children's Responses to Painful Pediatric Oncology Treatment Procedures, Journal of Psychosocial Oncology 30, p. 593-613.

Jabeen, K., Ashraf, M. S., Iftikhar, S., \& Belgaumi, A. F., 2016. The Impact of Socioeconomic Factors on the Outcome of Childhood Acute Lymphoblastic Leukemia (ALL) Treatment in a Low/middle Income Country (LMIC), Journal of Pediatric Hematology/oncology 38, p. 587-596.

Kazak, A. E., Barakat, L. P., Alderfer, M., Rourke, M. T., Meeske, K., Gallagher, P. R., ... \& Stuber, M. L., 2001. Posttraumatic Stress in Survivors of Childhood Cancer and Mothers: Development and Validation of the Impact of Traumatic Stressors Interview Schedule (ITSIS), Journal of Clinical Psychology in Medical Settings 8, p. 307-323.

Kazak, A. E., Boeving, C. A., Alderfer, M. A., Hwang, W. T., \& Reilly, A., 2005. Posttraumatic Stress Symptoms During Treatment in Parents of Children with Cancer, Journal of Clinical Oncology 23, p. 7405-7410.

Kohlsdorf, M., \& Costa Junior, Á. L., 2012. Psychosocial Impact of Pediatric Cancer on Parents: A Literature Review, Paidéia 22, p. 119129.

Kohn, R., Wintrob, R. M., Alarcon, R. D., 2009. Transcultural Psychiatry, in "Kaplan \& Sadock's Comprehensive textbook of psychiatry" B. J. Sadock, V. A. Sadock, P. Ruiz, Editor. Lippincott Williams \& Wilkins, Philadelphia, p. 735-753.

Manne, S. L., Jacobsen, P. B., Gorfinkle, K., Gerstein, F., \& Redd, W. H., 1993. Treatment Adherence Difficulties Among Children With Cancer: The role of Parenting Style, Journal of Pediatric Psychology 18, p. 47-62.

McGrath, P., Paton, M. A., \& Huff, N., 2005. Beginning Treatment for Pediatric Acute Myeloid Leukemia: The Family Connection, Issues in Comprehensive Pediatric Nursing 28, p. 97-114.

McGrath, P., 2001. Findings on the Impact of Treatment for Childhood Acute Lymphoblastic Leukaemia on Family Relationships, Child \& Family Social Work 6, p. 229-237.

Mogensen, H., Modig, K., Tettamanti, G., Erdmann, F., Heyman, M., \& Feychting, M., 2018. Survival After Childhood Cancer-Social Inequalities in High-Income Countries, Frontiers in Oncology 8, p. 485.

Mostert, S., Gunawan, S., Wolters, E., van de Ven, P. M., Sitaresmi, M. N., van Dongen, J., ... \& Kaspers, G. J. L., 2012. Socio-economic Status Plays Important Roles in Childhood Cancer Treatment Outcome in Indonesia, Asian Pacific Journal of Cancer Prevention 13, p. 6491-6496.

Mostert, S., Sitaresmi, M. N., Gundy, C. M., \& Veerman, A. J., 2006. Influence of Socioeconomic Status on Childhood Acute Lymphoblastic Leukemia Treatment in Indonesia, Pediatrics 118, p. e1600-e1606.

Okado, Y., Tillery, R., Howard Sharp, K., Long, A. M., \& Phipps, S., 2016. Effects of Time Since Diagnosis on the Association Between Parent and Child Distress in Families with Pediatric Cancer, Children's Health Care 45, p. 303-322.

Okumu, R. A., Muiva, M., Wagoro, M., Abdallah, F., \& Oweya, E., 2017. Association Between Socioeconomic and Psychological Experiences of Parents with Children on Leukemia Treatment in Kenyatta National Hospital, Kenya, Asia-Pacific Journal of Oncology Nursing 4, p. 38.

Osterberg, L., \& Blaschke, T., 2005. Adherence to Medication, New England Journal of Medicine 353, p. $487-497$.

Perricone, G., Polizzi, C., Morales, M. R., Marino, S., \& Scacco, C. F., 2012. Functioning of Family System in Pediatric Oncology During Treatment Phase, Pediatric Hematology and Oncology 29, p. 652-662.

Presiden Republik Indonesia. Kumpulan peraturan jaminan kesehatan. 2013 January 18 [accessed 22th February 2019]. Available from: http://www.depkes.go.id/resources/download/jkn/himpunan-peraturan-jaminan-kesehatan.pdf

Pritchard, M. T., Butow, P. N., Stevens, M. M., \& Duley, J. A., 2006. Understanding Medication Adherence in Pediatric Acute Lymphoblastic Leukemia: A Review, Journal of Pediatric Hematology/Oncology 28, p. 816-823.

Purnamasari, R., Rini, A. T., 2018. Persiapan kemoterapi, in “Buku Ajar Hematologi Onkologi Anak” E. Windiastuti, Y. M. Nency, S. Mulatsih, B. Sudarmanto, I. D. G. Urgasena, Editor. IDAI, Jakarta, p. 270-275.

Pusat Data dan Informasi Kementerian Kesehatan Republik Indonesia. Situasi penyakit kanker. 2015 Juny [accessed 2th February 2019]. Available from: http://www.depkes.go.id

Rabineau, K. M., Mabe, P. A., \& Vega, R. A., 2008. Parenting Stress in Pediatric Oncology Populations, Journal of Pediatric Hematology/Oncology 30, p. 358-365.

Smith, M. A., Seibel, N. L., Altekruse, S. F., Ries, L. A., Melbert, D. L., O'Leary, M., ... \& Reaman, G. H., 2010. Outcomes for Children and Adolescents with Cancer: Challenges for the Twenty-first Century, Journal of Clinical Oncology 28, p. 2625.

Streisand, R., Braniecki, S., Tercyak, K. P., \& Kazak, A. E., 2001. Childhood Illness-Related Parenting Stress: the Pediatric Inventory for Parents, Journal of Pediatric Psychology 26, p. 155-162.

Svavarsdottir, E. K., 2005. Gender and Emotions: Icelandic Parents Experiencing Childhood Cancer, International Journal of Nursing Studies 42, p. 531-538.

Wang, J., Shen, N., Zhang, X., Shen, M., Xie, A., Howell, D., \& Yuan, C., 2017. Care Burden and Its Predictive Factors in Parents of Newly Diagnosed Children with Acute Lymphoblastic Leukemia in Academic Hospitals in China, Supportive Care in Cancer 25, p. 3703-3713.

Wong, M. Y. F., \& Chan, S. W. C., 2006. The Qualitative Experience of Chinese Parents with Children Diagnosed of Cancer, Journal of Clinical Nursing 15, p. 710-717.

Yeh, C. H., 2002. Gender Differences of Parental Distress in Children with Cancer, Journal of Advanced Nursing 38, p. 598-606. 